\section{TORRES-RODRIGUEZ, Alicia y MORAL-PAJARES, Encarnación (coords.), 2018, Agua y ecología política en España y México, Jaén, UJA Editorial, 281 págs. ISBN 978-84-9159-126-9.}

El presente libro forma parte de una colección, editada en forma conjunta entre la Universidad de Jaén y la Universidad de Guadalajara, que tiene como propósito mostrar la interacción cultural, académica y científica en distintos aspectos de la gestión de los recursos hídricos. La obra presenta, desde la perspectiva teórica de la ecología política, los usos de los recursos bajo un debate teórico-metodológico, que permite analizar y explicar la explotación y sobreexplotación de éstos, tomando en cuenta cuáles son sus implicaciones económicas, políticas, sociales, sobre el medio ambiente en los espacios socio-territoriales.

El primer epígrafe está a cargo de Patricia ÁvilaGarcía titulado «El Estado y la cuestión del agua en el contexto de mundialización», donde pone énfasis en la dimensión social y política de la cuestión ambiental, a partir de las contradicciones y conflictos ecológicos-distributivos que genera el sistema económico dominante. Así pues, muestra los cambios en el sistema asociados a las políticas neoliberales, tales como la apertura comercial y la privatización de los recursos transformados en mercancías como es el caso del agua. La autora sostiene que el análisis de la acumulación por desposesión asociada con la privatización del agua brinda más poder económico y autonomía a las empresas, sobre todo a las trasnacionales.

También señala que la neoliberalización del agua en Latinoamérica ha fragmentado el territorio, separando la matriz agua-subsuelo-bosque que forma parte de la cosmovisión prehispánica al incluirla en la lógica del mercado como una entidad independiente. Lo anterior ha implicado el despojo de los territorios habitados con población indígena y campesina, restringiendo el acceso y control de manantiales, ríos, lagos y humedales, por la vía de la privatización de la tierra y bajo la justificación del beneficio social y nacional. En este contexto, los cambios en el modelo de apropiación y gestión del agua que beneficia al sector privado conllevan a nuevas formas de colonialismo del territorio, resistencia social y conflicto.

El segundo apartado «Ecología y servicios públicos: nuevas perspectivas y cambio de paradigma» a cargo de Juan Manuel Matés-Barco, analiza la relación entre empresa, sociedad y servicio público. Para lograrlo, el autor realiza un acercamiento a algunos de los máximos exponentes del Derecho Administrativo español, así como un minucioso análisis de la bibliografía reciente sobre el tema de servicios públicos. En este sentido, se examinan los cambios ocurridos en la gestión en este rubro en España, como resultado de una nueva conformación del territorio y la adopción de las políticas que derivan de los compromisos asumidos en el seno de la Unión Europea, que permiten un nuevo modelo de Estado y propician nuevas técnicas y cambios en la organización en los servicios públicos.

La regulación de la competencia, los organismos reguladores y la despublificación forman parte de los elementos esenciales del naciente arquetipo de servicios públicos que examina Matés- Barco. Otro elemento destacado es el importante papel de la regulación de los servicios esenciales a partir de la intervención del Estado, que debe buscar una mayor eficiencia y libertad.

El tercer capítulo recoge el trabajo realizado por Gregorio Núñez, donde aborda «La gestión de las aguas en España: fundamentos ecológicos, económicos y políticos del cambio institucional». Desde el enfoque de la ecología política y económica muestra cómo fueron gestionadas las aguas en España. Describe cómo la sociedad española del pasado se adaptó a las condiciones ambientales y cómo se ha buscado aumentar el volumen total de las aguas disponibles para riego, usos urbanos e industriales. El autor sostiene que la búsqueda de recursos hídricos y la diversificación de sus usos son los que determinan la oferta y la demanda del líquido, condicionados por la ecología y las instituciones. Además, muestra los mecanismos empleados en la gestión a corto plazo, así como las utilizadas a largo plazo, con una mayor presión de la demanda, donde se visibilizan los conflictos sociales y los acuerdos institucionales de alto nivel.

Leticia Gallego-Valero, Encarnación Moral-Pajares e Isabel Ma. Román-Sánchez abordan el capítulo referente a la «Tributación sobre aguas residuales en la Unión 
Europea: el caso de España». En él se estudian las tasas e impuestos sobre las aguas residuales en la Unión Europea, centrando su análisis en el caso de España, a través del estudio de la Directiva del Consejo Europeo de 21 de mayo de 1991, sobre tratamiento de las aguas residuales, y la Directiva Marco del Agua aprobada en 2000. Las autoras nos presentan la evolución del volumen de aguas residuales tratadas en España y examinan los distintos tipos de impuestos medioambientales que recaen sobre los efluentes, asociados al pago de externalidades negativas sobre el medio hídrico, que van a contribuir a la protección de la calidad de vida y permiten trasladar la responsabilidad a los agentes contaminantes haciendo efectivo el principio de «quien contamina, paga».

«Imaginación, innovación y ecología en la cultura del agua», escrito por Eloy Martos-Núñez y Aitana Martos-García muestran cómo el agua está vinculada a la historia y al patrimonio cultural y, a su vez, forman parte de los imaginarios sociales. En este artículo, los autores interrelacionan las distintas percepciones del recurso, presentando una aproximación crítica que da respuesta a la crisis ambiental. Se proponen desarrollar el conocimiento de este recurso como un bien cultural a proteger y compartir, vinculándolo con la sostenibilidad y la prevención de desastres ambientales. En este sentido, promueven la implementación de políticas públicas y el desarrollo de pautas educativas que contribuyan a una educación responsable de la sociedad.

Cecilia Lezama Escalante expone en su artículo «Las empresas trasnacionales en el proceso de privatización del agua en México» el incremento de empresas trasnacionales instaladas en el sector de los servicios de suministro de agua potable y saneamiento. Para ello se abordan los antecedentes de las principales compañías en el sector agua y su expansión en algunos países latinoamericanos. Dado que la privatización del agua se puede llevar a cabo por distintas vías, la autora hace referencia únicamente aquella donde «las empresas prácticamente se apropian de la infraestructura hidráulica de redes de distribución y fijan las tarifas del agua». Su interés está centrado en exponer las vías que conducen al proceso de privatización del agua a partir de la expansión de las empresas trasnacionales. En este sentido, se muestra cómo a partir del nuevo orden económico, el agua ha dejado de considerarse como un derecho universal, para convertirse en un bien económico, es decir, privatizado.

Por otro lado, Alicia Torres Rodríguez en su texto «Repensando las políticas de desarrollo regional: cambios económicos, sociales e hidroterritoriales en la cuenca Lerma-Chapala-Santiago» analiza la diferenciación entre las regiones que conforman esta zona como resultado de la implementación de las políticas públicas en la materia. Examina cómo los distintos proyectos hidráulicos que se construyeron a lo largo de este cuerpo de agua (presas para la generación de energía eléctrica, riego y abastecimiento urbano), así como otras obras de infraestructura que retienen o desvían el cauce natural de los ríos transformaron la cuenca. En esta dinámica, la autora reflexiona sobre el impacto de los desechos urbanos e industriales vertidos en estos cuerpos de agua que han desencadenado en grandes problemas ambientales. Así pues, se plantea la necesidad de hacer una revisión a las políticas de desarrollo regional con el objetivo de desplegar proyectos que ayuden a mitigar el daño ocasionado.

Aida Alejandra Guerrero-de León en coautoría con Peter R. W. Gerritsen, María Azucena Arellano-Avelar y Alberto Daniel Rocha-Muñoz presentan «Salud y contaminación del río Santiago y río Ayuquila en México». En su trabajo, los autores estudian los problemas socioambientales ocasionados en el río Santiago, uno de los cinco más contaminados de México por desechos agrícolas, urbanos e industriales. Su artículo tiene como objetivo analizar las percepciones sociales sobre el agua, a partir de un estudio descriptivo socioambiental, entrevistas y encuestas, en cuatro municipios localizados en contextos geográficamente distintos: El Salto y Juanacatlán, que pertenecen a la Cuenca del Río Santiago, y Autlán de Navarro y Tuxcacuesco, ubicado en la Cuenca del Río Ayuquila. El texto nos muestra que en México aún falta mucho trabajo por hacer en temas de salud ambiental y participación social.

El siguiente capítulo recoge el trabajo realizado por Octavio M. González titulado «Privatización de la tierra y el agua a paso lento: la introducción de la avicultura en el Bajío Michoacano». En él se explora el proceso de cambio de uso de suelo, en este caso de uno de carácter agrícola a uno avícola, a través de la privatización de la tierra y el agua ocurridas en zonas de propiedad ejidal de la región del Bajío michoacano. Se señala que en las décadas de los años de 1980 y 1990 se flexibilizó el marco legal lo que dio entrada, a partir de las políticas neoliberales, a la privatización, afectando de manera profunda a la propiedad de las tierras ejidales y comunales. Para ello, se expone un estudio de caso, representado por una empresa, y la exposición del proceso de compra de tierras y aguas en la región del Bajío que permiten esbozar las implicaciones regionales de dicho proceso. 
Por último, María Luisa Torregrosa, Karina Kloster y Jade Latargère finalizan con «Tierra y agua: territorios en construcción en Milpa Alta, Ciudad de México». Su objetivo es contribuir a hacer observables los múltiples mecanismos de abasto de agua encontrados en Milpa Alta, zona periurbana del Distrito Federal donde las formas de acceso al agua y los mecanismos de apropiación y uso del espacio, así como los procesos, actores y estrategias involucradas. Así pues, se pretende comprender su correspondencia con la construcción de un espacio regulado por el Estado y otro que se apropian los grupos sociales.

Para concluir, es preciso señalar que el libro supone un gran avance porque logra reunir los trabajos de distintos ámbitos de carácter socioambiental: economis- tas, politólogos, geógrafos, antropólogos, historiadores, biólogos, expertos en los usos del agua, el territorio y medio ambiente, ingenieros y médicos, lo que le da a la obra una visión multi e interdisciplinar. Por otro lado, presenta problemáticas de dos países con diferencias y semejanzas de gran importancia para las ciencias sociales y humanas y que permite hacer diversas lecturas de referentes empíricos bien dibujados por investigadores de España y de México con relación al acceso al agua.

José Raúl Reyes-Ibarra Instituto de Investigaciones

Dr. José María Luis Mora jrreyes@institutomora.edu.mx 